\title{
Relationship between propulsive force of the arm, body composition and isokinetic muscle strength indicators in surfers
}

\section{Relação entre a força propulsiva da braçada, composição corporal e indicadores de força muscular isocinética em surfistas}

\author{
Sidarta Oliveira Geber ${ }^{1}$ \\ Bruno Remígio Cavalcante ${ }^{1,2}$ \\ Antônio Henrique Germano-Soares ${ }^{1,2}$ \\ Raysa Catarina Cavalcante Figueiredo Montes \\ Arthur Henrique Oliveira Silva ${ }^{1}$ \\ Túlio Samuelson Martins Veloso \\ José Raphael Leandro da Costa Silva ${ }^{1,2}$ \\ Marcos André Moura Santos ${ }^{1,2}$
}

Abstract - This study aimed to evaluate the potential relationship between body composition (percentage of fat mass (FM \%), fat mass and lean mass), muscle function (i.e., muscles; deltoid side and front, pectoralis major and teres major) and the propulsive force of the arm (PFA). Sixteen competitive surfers $(29.1 \pm 7.3$ years; $1.72 \pm 0.06 \mathrm{~m} ; 74.2 \pm 1.4$ $\mathrm{kg}$ ) were assessed for height, body mass, body composition (dual-energy-DXA), muscle function and PFA. Pearson correlation analyses were used to verify the relationship between all variables. An inverse correlations were found between PFA and isokinetic parameters to $60 \%$ s: external rotation (peak torque: $r=-0.71 ; p=0.014$; total work: $r$ $=-0.75 ; p=0.007$; power: $r=-0.72 ; p=0.011$ ) and internal rotation (peak torque: $r=$ $-0.61 ; p=0.045$; total work: $r=-0.73 ; p=0.010$; power: $r=-0.61 ; p=0.045)$ and $300 \%$ s: external rotation (peak torque: $r=-0.79 ; p=0.003$; total work: $r=-0.84 ; p<0,001$; power: $r=-0.81 ; p=0.002$ ) and internal rotation (peak torque: $r=-0.69 ; p=0.017$; total work: $r=-0.72 ; p=0.011$; power: $r=-0.69 ; p=0.017$ ). There was no significant correlation between body composition components and PFA $(p>0.05)$. Although correlations do not imply cause and effect, PFA is not correlated with body composition in surfers and these relationships are inversely related to the parameters of muscle function.

Key words: Anthropometry; Body size; Physical fitness; Upper extremity.

Resumo - Objetivou-se avaliar a potencial relação entre a composição corporal (percentual de gordura (\% gord.), massa gorda e massa magra), função muscular (i.e., músculos; deltoide anterior, deltoide lateral, peitoral maior e redondo maior) e a força propulsiva da braçada (FPB). Dezesseis surfistas competitivos $(29,1 \pm 7,3$ anos, 1,72 $\pm 0,06 \mathrm{~m}, 74,2 \pm 1,4 \mathrm{~kg})$ tiveram a altura, massa corporal, composição corporal (dual-energy-DXA), função muscular e FPB avaliados. $O$ coeficiente de correlação de Pearson foi empregado para avaliar a relação entre todas as variáveis. Foram observadas relaçôes inversas entre a FPB e os parâmetros isocinéticos a $60 \%$ s: rotação externa (pico de torque: $r=-0,71 ; p=0,014$; trabalho total: $r=-0,75 ; p=0,007$; potência: $r$ $=-0,72 ; p=0,011$ ) e rotação interna (pico de torque: $r=-0,61 ; p=0,045$; trabalho total $=r=$ $-0,73 ; p=0,010$; potência: $r=-0,61 ; p=0,045$ ) e 300/s: rotação externa (pico de torque: $r=$ $-0,79 ; p=0,003$; trabalho total: $r=-0,84 ; p<0,001$; potência: $r=-0,81 ; p=0,002$ ) e rotação interna (pico de torque: $r=-0,69 ; p=0,017$; trabalho total: $r=-0,72 ; p=0,011$; potencia: $r$ $=-0,69 ; p=0,017)$. Não foram observadas correlaçôes significativas entre os componentes da composição corporal e a FPB ( $p>0,05)$. Embora as correlaçôes não impliquem em causa e efeito, a FPB não está correlacionada com a composição corporal em surfistas e estas relações são inversas com os parâmetros da função muscular.

Palavras-chave: Antropometria; Aptidão física; Membros superiores; Tamanho corporal.
1 University of Pernambuco. Superior School of Physical Education. Recife, PE. Brazil.

2 University of Pernambuco. Associated graduate Program in Physical Education. Recife, PE. Brazil.

Received: August 25, 2017 Accepted: April 17, 2018

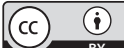




\section{INTRODUCTION}

Surfing is an activity characterized by intermittent exercise varying intensities, durations and recovery periods, as also involving different body parts $^{1}$. These intensities and durations differ as a result of the environmental conditions (e.g., wave formation, type of wave break, wave size, weather, currents, and frequency of waves) encountered at the surfing site $^{2}$. For example, surfing competition takes places under a variety of conditions that have a large effect on activity patterns, such as duration of wave riding and time spent paddling ${ }^{3}$. The type of wave break and changing conditions such as wind, swell, and tide conditions greatly influence the nature of the surfing activity. In this scenario, the activity profile of surfers has been previously described with surfers participating in activities of waiting (28-42\% of total time), paddling (35-54\% of total time), riding (3.8-8\% of total time) and miscellaneous activities $(2.5-5 \% \text { of total time })^{3,4}$.

Therefore, surfing athletes are required to have well developed muscular endurance, cardiorespiratory fitness, and anaerobic power, particularly of the upper torso ${ }^{5}$. Trying to understand the dynamics of the surfer at the moment of paddling for a wave, studies were carried out using a surf-specific paddle ergometer to measure performance in terms of speed and resistance ${ }^{6,7}$. For example, Loveless and Minahan ${ }^{6}$ evaluated the peak power and peak speed in 11 male surfers, during six 10-s maximal-intensity paddling tests on a swimbench ergometer (laboratory tests). In addition, peak speed was measured during six 10-s maximal-intensity paddling tests performed in a swimming pool (field tests). There were no differences among the laboratory and field tests. Further, intraclass correlation coefficients for the laboratory and field test were 0.98 and $0.99(p<0.01)$, respectively. These authors concluded that, maximalpaddling performance can be measured reliably both in the laboratory during swim-bench ergometry and in the field in a swimming pool ${ }^{6}$. However, it would seem more appropriate and indeed more practical, to evaluate paddling ability with surfers in the water to provide greater context validity ${ }^{8}$.

In surfers, the isokinetic dynamometry has been used to evaluate upper as well as lower limbs strength ${ }^{9-11}$. However, different actions and protocols have been used in their evaluation. On the other hand, the literature on the use of ergometers to test swimmers and surfers' anaerobic power has established their reliability ${ }^{6,12}$. In addition, studies have shown high correlations between swimming performance and power outputs obtained from swim bench ergometry testing ${ }^{6,13-15}$, supporting the theory that swim bench power output is a potentially useful indicator of performance. To the best of our knowledge, this is perhaps the first study to use this approach, e.g., to measure and investigate the relationship between the propulsive force of the arm in competitive surf athletes using an adapted specific ergometer inside the pool (field tests) and isokinetic muscle strength (laboratory test). Our hypothesis is that there is a linear relationship between the propulsive force of the arm and body compositions components and the muscle function will be associate with the higher levels of propulsive force. 
This is an important issue since the assessment of muscle function related to sprint paddling could be useful in guiding coaching decisions and providing a basis for strength training in surfers ${ }^{16}$. Thus, the aim of this study was to analyze the relationship between the propulsive force of the arm, body composition and muscle function of competitive surfers.

\section{METHODOLOGICAL PROCEDURES}

\section{Participants}

Sixteen competitive male surfers (age $29 \pm 7$ years) who practiced surf in the Pernambuco sea coast for at least eight years, were included. At the time of the study, the participants were actively (in season) competing in, as a minimum standard, domestic "open" competition, with most of them competing at National and International Surfing Association Series events. The participants were tested following their normal routine of nutrition and hydration levels before testing. The main criterion of inclusion in this study was recorded at the Brazilian Federation of Surf. None of the volunteers subjected to the measures and tests were excluded from the study. All participants received a clear explanation of the study, including the risks and benefits of participation, and they could refuse to participate in the study at any time. All included participants provided written informed consent for testing and data analysis. The Research Ethics Committee of the University of Pernambuco approved the study procedure which followed established norms of the National Research Ethics Commission (CONEP/UPE: 026146/2015). All the procedures adhered to the guidelines of the Declaration of Helsinki (www. wma.net/e/policy/b3.htm). The tests were carried out in two days. On the first day, anthropometry, body composition and isokinetic tests were performed, and on the second day (i.e., after 48 hours), the propulsive force of the arm.

\section{Anthropometry and Body Composition (DXA assessment)}

All measurements were taken according to standardized procedures ${ }^{17}$. The body mass was measured to the nearest $0.1 \mathrm{~kg}$ on a Filizola scale (Filizola ${ }^{\oplus}$ São Paulo, Brazil) with subject lightly dressed and barefooted; stature was measured to the nearest $0.5 \mathrm{~cm}$ using a portable stadiometer (Sanny, São Paulo, Brazil), and the participants were barefoot, feet together, and head in the Frankfurt plane. Body Mass index (BMI) was calculated using the standard formula (body mass $[\mathrm{kg}] /$ height $^{2}[\mathrm{~m}]$ ).

DXA (Prodigy with software version 9.3; GE Lunar, Madison, WI) was used to measure total Fat Mass, percentage of Fat Mass (FM \%), and Lean Mass. All metal items were removed from the participants to ensure the accuracy of the measurement. The participants were positioned in the center of the table for each scan. They were scanned using the default scan mode automatically selected by the Prodigy software. The whole procedure lasted between 5 and 10 minutes and was performed by the same technician who calibrated equipment according to the manufacturer's recommendations. Precision of the repeated measurements expressed as the percent coefficient of variation was $2.2 \%$ for FM\%. 


\section{Isokinetic Testing}

Concentric and eccentric parameter measures on the dominant and non-dominant shoulder were performed on isokinetic dynamometer (Biodex System 3 Pro - Biodex Corp. Shirley, NY, USA) at speeds of $60 \%$ and $300 \%$. These speeds were used to represent maximum strength and resistance force, respectively. The participants completed three to five submaximal contractions trials to become familiar with the procedure and to warm up their muscles. The dominant arm was assessed first, then the non-dominant arm. Information from the dominant and non-dominant arm was given by the surfer at the time of the test. During the test, the participants were in a sitting position, with the shoulder at $45^{\circ}$ abduction in Internal Rotation (frontal plan) and $90^{\circ}$ elbow flexion, a position previously recommended by other investigators ${ }^{18,19}$.

The participants, who were fixed to the seat with belts around the trunk and pelvis in order to avoid compensatory movements, began the exercises by performing about $90^{\circ}$ range of motion in External Rotation (ER). The positioning of the participants and the joint alignment were done according to the instructions set out in the device's operations handbook ${ }^{20}$. In this study, tests started from internal rotator concentric contraction at the speed of $60 \%$ and then eccentric contraction at the same speed. Test speed was increased to $300 \%$ when the tests at low speed were finished. The external rotation test at $60 \%$ followed the internal rotation tests. Again, the external rotation concentric test was started first, and then the eccentric test and the speed were increased to $300 \%$ when the tests at low speed were finished.

\section{Propulsive force of the arm (PFA)}

Propulsive force of the arm testing was conducted in an outdoor $25-\mathrm{m}$ swimming pool. All participants used their own surfboard for the testing (the one they use in competition) to provide context validity. To determine the propulsive force of the arm (PFA) during the sprint-paddle the tied swimming test protocol proposed by Papoti et al., was used ${ }^{21}$. The protocol tries to simulate real situations during the batteries in competitions. A cable of mild steel, $1.27 \mathrm{~cm}$ thick and $3 \mathrm{~m}$ long was attached to the waist of the surfer, which in turn was connected to a dynamometer (Ergometer Globus, Codigné, Italy) that remained bonded to record the surfer's strength.

A 10-minute warm-up period of exercise subjectively determined by the surfer as moderate intensity was performed before the beginning of the tests. After warming up, the participants remained on the board, thus the movements could be carried out exclusively by the upper limbs. The adapted test consisted of applying two sets of maximal efforts lasting 30 seconds and four minutes of rest between sets. To estimate the relative reliability, we used the ANOVA-based intraclass correlation coefficients $(R)$ and respective $95 \%$ confidence intervals using the first and second sets of maximal efforts. The $R$ values was 0.90 (95\%CI: 0.74 to 0.96 ).

In the present study, we only used the maximal effort (kgf) that were analyzed in the Software EMG System, [(EMG Lab V1.2) EMG System, 
SP, Brazil]. The propulsive force of the arm data from the dynamometer were sampled at $100 \mathrm{~Hz}$. Signals were filtered with a 0-35 Hz band-pass second-order Butterworth. The beginning and end of the test were determined by an audible signal (whistle) and all participants were verbally encouraged to make maximum efforts at a maximum speed. Propulsive force of the arm measurements for each athlete were obtained by the usage of a dynamometer (model DTC/200 - EMG System, Brazil), comprising a load cell, hardware, and software. The load cell was a force transducer with a traction capacity of $200 \mathrm{~kg}$.

\section{Statistical analysis}

Exploratory data analysis was used to identify potentially inaccurate information and outliers. The normality and homogeneity of the data were confirmed by the Shapiro-Wilk and Levene tests. Descriptive statistics are presented as means and standard deviations. Correlations between propulsive force of the arm and isokinetic parameters (peak torque, total work, power) in internal and external rotation, were tested using the Pearson's product-moment correlation coefficient. Statistical analyses were performed using software SPSS (version 17.0 for windows). The level of significance was set at $5 \%$.

\section{RESULTS}

Basic descriptive information of the sample are shown in Table 1.

Table 1- Sample descriptive characteristics (mean with SD) ( $n=16)$.

\begin{tabular}{lc}
\hline & Mean $\pm \mathrm{SD}$ \\
\hline Variables & $29 \pm 7$ \\
\hline Age (years) & $74 \pm 10$ \\
\hline Body Mass $(\mathrm{kg})$ & $1.72 \pm 0.06$ \\
\hline Height $(\mathrm{m})$ & $24.7 \pm 2.0$ \\
\hline Body mass Index $\left(\mathrm{kg} / \mathrm{m}^{2}\right)$ & $8 \pm 0.6$ \\
\hline Years experience $($ years) & \\
Propulsive force and Muscle Function & $48.6 \pm 5.7$ \\
\hline PFA (kgf) & $43.1 \pm 8.1$ \\
\hline Peak torque in external rotation $60 \% \mathrm{~s}(\mathrm{~N} \cdot \mathrm{m})$ & $65.3 \pm 14.2$ \\
\hline Peak torque in internal rotation $60 \% \mathrm{~s}(\mathrm{~N} \cdot \mathrm{m})$ & $44.6 \pm 8.5$ \\
\hline Total work in external rotation $60 \% \mathrm{~s}(\mathrm{~J})$ & $65.8 \pm 16.0$ \\
\hline Total work in internal rotation $60 \% \mathrm{~s}(\mathrm{~J})$ & $33.5 \pm 6.3$ \\
\hline Power in external rotation $60 \% \mathrm{~s}(\mathrm{~W})$ & $48.5 \pm 12.2$ \\
\hline Power in internal rotation $60 \% \mathrm{~s}(\mathrm{~W})$ & $52.2 \pm 10.7$ \\
\hline Peak torque in external $300 \% \mathrm{~s}(\mathrm{Nm})$ & $64.6 \pm 17.7$ \\
\hline Peak torque in internal $300 \% \mathrm{~s}(\mathrm{~N} \cdot \mathrm{m})$ & $38.7 \pm 9.5$ \\
\hline Total work in external rotation $300 \% \mathrm{~s}(\mathrm{~J})$ & $53.6 \pm 16.4$ \\
\hline Total work in internal rotation $300 \% \mathrm{~s}(\mathrm{~J})$ & $81.1 \pm 24.8$ \\
\hline Power in external rotation $300 \% \mathrm{~s}(\mathrm{~W})$ & $117.6 \pm 40.6$ \\
\hline Power in internal rotation $300 \% \mathrm{~s}(\mathrm{~W})$ & \\
\hline
\end{tabular}

SD: standard deviation: PFA: Propulsive force of the arm 
The Figure 1 shows the relationship between the propulsive force of the arm (PFA) and body composition. There were no significant correlations between PFA and fat mass, lean mass and body fat percentage (\%).

PFA was negatively correlated with all parameters of isokinetic muscle function at external and internal rotation of the shoulder to $60 \% \mathrm{~s}$ and $300 \%$ (Figure 2 and 3, respectively).
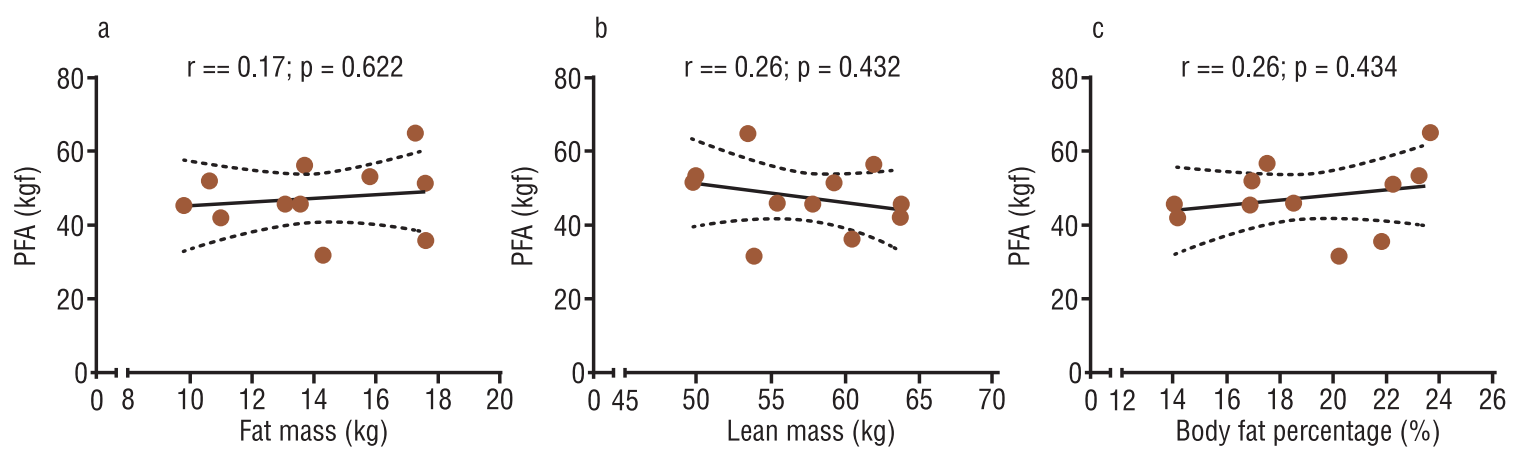

Figure 1 - Correlations between propulsive force of the arm and (PFA) and the body compositions indicators $(n=16)$. PFA- Propulsive force of the arm.
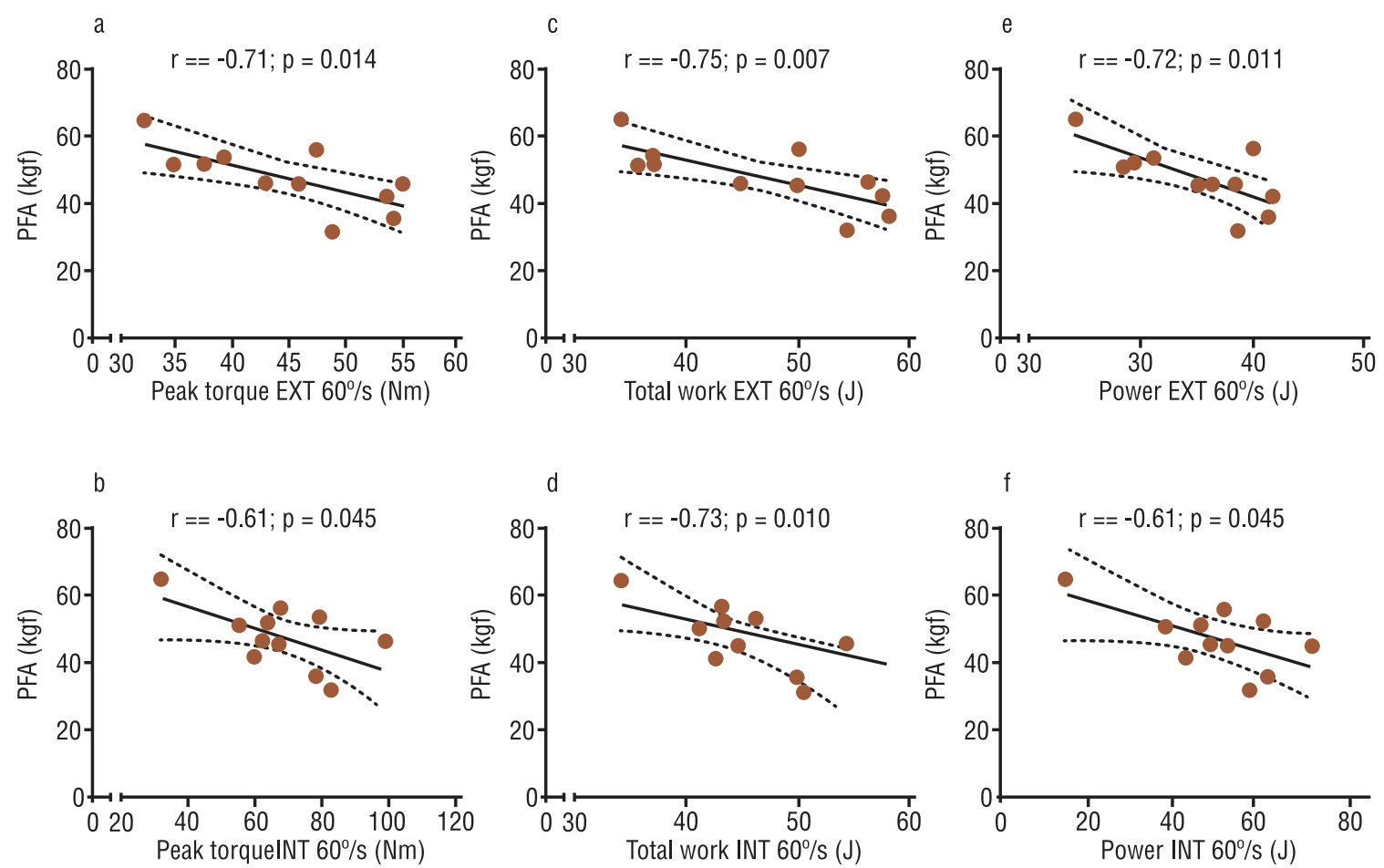

Figure 2 - Correlations between propulsive force of the arm (PFA) and indicators of isokinetic function to $60 \%$ ( $n=16)$. PFA - Propulsive force of the arm; PT- Peak torque in external rotation (a) and internal (c); Total Work- Total work in external (b) and internal rotation (d); $P W$ - Power in external (e) and internal rotation $(\mathrm{f})$.

\section{DISCUSSION}

In the present study, we analyzed the relationship between the propulsive force of the arm, body composition and muscle function of competitive surfers. To our knowledge, this is perhaps the first study that analyzed body composition (DXA) and muscle function in surfers (isokinetic dy- 

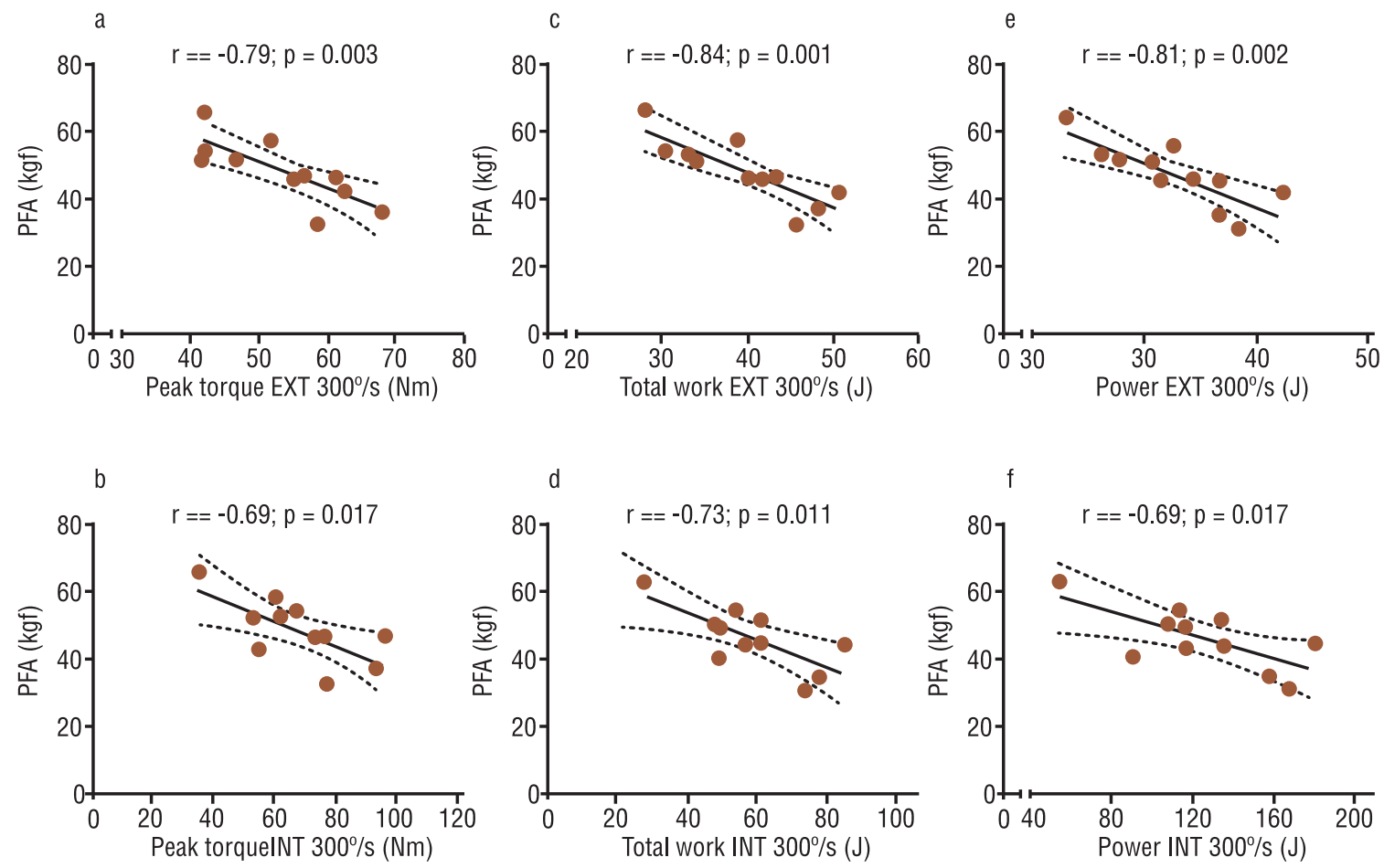

Figure 3 - Correlations between propulsive force of the arm (PFA) and indicators of isokinetic function to $300 \%$ ( $n=16)$. PFA - Propulsive force of the arm; PT- Peak torque in external (a) and internal rotation (c); Total Work- Total work in external (b) and internal rotation (d); PW- Power in external rotation (e) and internal (f).

namometer) with the adapted test to measure the propulsive force of the arm during the paddle. Contrary to our hypothesis, in the present study there were no significant relationships between PFA and body composition components (\%fat and FFM). However, these results seem to be aligned with previous studies that have analyzed the body composition of surfers. For example, Barlow et al. ${ }^{1}$ according to anthropometric evaluation, reported that surfers present a wide range of body fat values, suggesting no ideal body fat level related to surfing performance ${ }^{1,4}$. As a surfer's mass is supported while paddling and riding, low adiposity appears not to represent a real advantage from a performance perspective. Another study, with ten competitive male surfers $(23.9 \pm 6.8$ years, $177.0 \pm 6.5 \mathrm{~cm}, 72.2 \pm 2.4 \mathrm{~kg})$ did not find a strong association between lower skinfold thickness or the lean mass ratio and sprint paddling ability ${ }^{16}$. Therefore, anthropometric analyses of surfers have revealed that surfer's body composition appears not to play a major role in surfing performance ${ }^{22,23}$. Generally, estimated percentage body fat in surfers is higher than that reported in other level-matched endurance athletes ${ }^{1,24}$.

The neuromuscular system's ability to produce power at the highest exercise intensity, often referred as a 'muscular power' is an important determinant of athletic performance in surfers ${ }^{2}$. Taking this into account, the main idea behind to the second finding was to try to understand if the strength produced in water (i.e., simulated condition) is related in the same sense with the fixed movement of the shoulder at $45^{\circ}$ abduction in Internal Rotation (frontal plan) and $90^{\circ}$ elbow flex, a position previously recommended by 
other investigators ${ }^{18,19}$. Surprisingly, we observed that PFA was negatively correlated with all parameters of isokinetic muscle function independent of external or internal rotation of the shoulder to $60 \%$ and $300 \%$.

Notwithstanding these results, this is the first study to comprehensively evaluate the propulsive force of the arm and indicators of isokinetic function in surfers. Although we acknowledge that correlations do not imply cause and effect and that the magnitude of the relationship is inverse and only moderate (although significant), it could be speculated that higher levels of strength in isokinetic action does not represent a direct transference in the capacity of production of force with the arms in surf.

However, using another methodology Sheppard et al., ${ }^{24}$ found strong associations between relative (total kilograms lifted per athlete mass) upper-body pulling strength and sprint paddling time to 5,10 , and $15 \mathrm{~m}$ $(r=-0.94,-0.93,-0.88$, respectively) and peak sprint paddling velocity $(r=0.66)$. This result suggests that surfers require highly developed upperbody pulling strength, but this must be accompanied by low-fat mass to optimize their relative upper-body strength score ${ }^{24}$.

In the present study, is necessary to consider, that the PFA is realized in 30 seconds and isokinetic muscle function is determined in 10 or 20 seconds during the action at the dynamometer and these conditions could reduce the likelihood of finding a positive association between indicators of isokinetic function and sprint paddling performance. However, a 10-second sprint-paddle assessment has previously been demonstrated to be a reliable method to evaluate paddling ability in surfers ${ }^{6}$ and sprintpaddling ability has been shown as a relevant skill to assess in competitive surfers ${ }^{25}$. Besides, is important to observe that during the action of isokinetic function the acceleration is "zero", and this fact can change the direction of the relationship.

Another relevant aspect is that during the test of the propulsive force of the arm all surfers used their own surfboard, which is relative to their body mass and height. Under this condition is possible that the capacity of flotation increase the differences between the participants and influencing the understanding of this relationship. However, using another kind of ergometer Farley at al., ${ }^{22}$ determined the peak oxygen uptake $\left(\mathrm{VO}_{2}\right.$ peak) from an incremental ramp test and anaerobic power (watts) during a 10-second maximal paddling burst using a surf paddle-specific modified kayak ergometer, customized with a surfboard and hand paddles. The results showed a significant relationship between anaerobic power and season $\operatorname{rank}(r=-0.55, p=0.05)$. For these authors, although correlations do not imply cause and effect, such a finding provides theoretical support for the importance of including anaerobic paddling power in assessment batteries and conditioning practice for surf athletes ${ }^{15}$.

Although the results are controversial, it is important highlight that the body in a constant velocity has its null tangential acceleration, since acceleration is the temporal rate of change of velocity. So, if this does not change in time, the acceleration will be zero (i.e., in the isokinetic 
dynamometer the velocity is constant). We must remember, however, that in a uniform circular motion (i.e., actions of the arm during the paddle), even the tangential velocity being constant and its tangential acceleration being zero, there is an acceleration which is the centripetal ${ }^{26}$.

The application of the findings of this study should aid the strength and conditioning coach in creating training protocols designed to increase maximal-paddling power for surfers considering the specific muscle actions, mainly if we considered the inverse relationship. Conceivably, improvements to maximal-paddling power output might improve surfing performance. Notwithstanding the relevance of our results, some limitations should be acknowledged. Firstly, the lack of specificity of the adapted test in the evaluation of the propulsive force of the arm and we analyze the maximum force reached in the time of 30 seconds. In addition, another limitation is that we did not remove the first cycle of arm and/ or a few seconds from the start of the test. However, the values found in the reliability analysis support the findings of this study. Nonetheless, this study has strengths, such as the force determination in isokinetic dynamometer and the fact that the test was performed in a simulated situation (field tests), which increases the ecological validity of the study. Clearly, more studies with a larger sample are needed to provide further information on these measures and these associations.

\section{CONCLUSION}

The propulsive force of the arm is negatively related with all parameters of isokinetic muscle function. However, there is no related with the components of body composition of surfers. Because propulsive force is highly responsive by the performance in surf, studies are necessary to investigate the potential effect of propulsive force of the arm when contrasted with positive stimuli of strength training or functional training. An increase in research of the sport will add to the overall level of professionalism within surfing and raise awareness of the benefits of certain training methodologies developed from performance analysis.

\section{Acknowledgments}

The authors wish to acknowledge the participation of the surfers involved during the research and Dra. Maria Emilia Monteiro Higino da Silva Moura for the contribution in the article revision.

\section{REFERENCES}

1. Barlow MJ, Findlay M, Gresty K, Cooke C. Anthropometric variables and their relationship to performance and ability in male surfers. Eur J Sport Sci 2014;14(Suppl 1):S171-7.

2. Farley OR, Abbiss CR, Sheppard JM. Performance Analysis of Surfing: A Review. J Strength Cond Res 2017;31(1):260-71.

3. Mendez-Villanueva A, Bishop D, Hamer P. Activity profile of world-class professional surfers during competition: a case study. J Strength Cond Res 2006;20(3):477-82. 
4. Barlow MJ, Gresty K, Findlay M, Cooke CB, Davidson MA. The effect of wave conditions and surfer ability on performance and the physiological response of recreational surfers. J Streng th Cond Res 2014;28(10):2946-53.

5. Mendez-Villanueva A, Bishop D. Physiological aspects of surfboard riding performance. Sports Med 2005;35(1):55-70.

6. Loveless DJ, Minahan C. Two reliable protocols for assessing maximal-paddling performance in surfboard riders. J Sports Sci 2010;28(7):797-803.

7. Loveless DJ, Minahan C. Peak aerobic power and paddling efficiency in recreational and competitive junior male surfers. J Sport Sci 2010;10(6):407-15.

8. Sheppard JM, Nimphius S, Haff GG, Tran TT, Spiteri T, Brooks H, et al. Development of a comprehensive performance-testing protocol for competitive surfers. Int J Sports Physiol Perform 2013;8(5):490-5.

9. Silvas MN, Howden ME, Mandel EK, Cummins KM, Nessler JA, Newcomer SC. Knee Extension and Flexion Strength in Recreational Surfers. Med Sci Sports Exerc 2015;47(5S):358.

10. Furness J. Musculoskeletal and physiological profile of elite and recreational surfers: injuries and sports specific screening: Bond University; 2015.

11. Danucalov MÁ, Ornellas FH, Navarro F. Força muscular isocinética, perfil de surfistas brasileiros. Rev Bras Cienc Mov 2010;17(4):78-82.

12. Swaine IL. Arm and leg power output in swimmers during simulated swimming. Med Sci Sports Exerc 2000;32(7):1288-92.

13. Morton D, Gastin P. Effect of high intensity board training on upper body anaerobic capacity and short-lasting exercise performance. Aust J Sci Med Sport 1997;29(1):17-21.

14. Sharp RL, Troup JP, Costill DL. Relationship between power and sprint freestyle swimming. Med Sci Sports Exerc 1982;14(1):53-6.

15. Farley O, Harris NK, Kilding AE. Anaerobic and aerobic fitness profiling of competitive surfers. J Strength Cond Res 2012;26(8):2243-8.

16. Sheppard JM, McNamara P, Osborne M, Andrews M, Borges TO, Walshe P, et al. Association between anthropometry and upper-body strength qualities with sprint paddling performance in competitive wave surfers. J Strength Cond Res 2012;26(12):3345-8.

17. Marfell-Jones M, Stewart A, de Ridder J. International standards for anthropometric assessment; 2012.

18. Tyler TF, Nahow RC, Nicholas SJ, McHugh MP. Quantifying shoulder rotation weakness in patients with shoulder impingement. J Shoulder Elbow Surg 2005;14(6):570-4.

19. Julienne R, Gauthier A, Moussay S, Davenne D. Isokinetic and electromyographic study of internal and external rotator muscles of tennis player. Isokinet Exerc Sci 2007;15(3):173-82.

20. Wilk K. Isokinetic Testing-Setup and Positioning. Biodex System II Manual, Applications/Operations; 1991.

21. Papoti M, Martins L, Cunha S, Zagatto A, Gobatto C. Padronização de um protocolo específico para determinação da aptidão anaeróbia de nadadores utilizando células de carga. Rev Port Cienc Desporto 2003;3(3):36-42.

22. Farley OR, Harris NK, Kilding AE. Physiological demands of competitive surfing. J Strength Cond Res 2012;26(7):1887-96.

23. Mendez-Villanueva A, Bishop D. Physiological aspects of surfboard riding performance. Sports Med 2005;35(1):55-70.

24. Sheppard JM, McNamara P, Osborne M, Andrews M, Oliveira Borges T, Walshe $\mathrm{P}$, et al. Association between anthropometry and upper-body strength qualities with sprint paddling performance in competitive wave surfers. J Strength Cond Res 2012;26(12):3345-8.

25. Sheppard J, Osborne M, Chapman D, Andrews M. Anthropometric characteristics, upper-body strength, and sprint paddling performance in competitive surfers. J Aust Strength Cond 2012;20(1):5-10.

26. McGinnis P. Biomechanics of sport and exercise: Human Kinetics; 2013.

CORRESPONDING AUTHOR

Marcos André Moura dos Santos Physical Education School,

University of Pernambuco.

Arnóbio Marques street, 310. Santo

Amaro, Zip code: 50100-130

Recife, PE - Brazil.

E-mail:mmoura23@gmail.com 